\title{
A Theoretical Analysis of Financial Agglomeration in China Based on Information Asymmetry
}

\author{
Xinwei CHE \\ School of Business, Renmin University of China, Beijing 100872, China \\ E-mail: chexinwei@hotmail.com \\ Hui BU \\ School of Economics and Management, Beihang University, Beijing 100191, China \\ E-mail: buhui@buaa.edu.cn \\ John J. LIU \\ Centre for Transport, Trade and Financial Studies (CTTFS), College of Business, City University of \\ Hong Kong \\ E-mail: johnliu@cityu.edu.hk
}

\begin{abstract}
The development of financial centers can illustrate continuous significance of geography. This paper regards financial services industry as a special kind of industry, and establishes a multiregion model to discuss the formation mechanism and equilibrium of finance agglomeration. Our findings suggest emergence of finance agglomeration depends on opportunity costs caused by information asymmetry, economies of scale, the share of financial services industry in economy and the amount of financial information. The results of numerical examples declare the same conclusions that effects of information asymmetry would push financial firms closer to an information source in order to find and interpret non-standardized information that a financial firm can use to make profit. And the agglomeration of real sector industry will enhance the agglomeration of finance. Finally, this paper puts forward a ratio, related with the opportunity costs, which could be regarded as a measure of whether the central area is an information center.
\end{abstract}

Keywords financial centers; information asymmetry; agglomeration; equilibrium; multi-region model

\section{Introduction}

The development of modern information technology has brought about a lot of changes to the microstructure and pattern of financial markets. The transmission of goods, capital and information can be realized among different areas efficiently and in low cost. Accordingly, some scholars believe that with sophisticated networks of electronic communications and electronic money, the circulation of capital is no longer obstructed by distance for financial industry. Despite the fact that electronic transmission of information has substantially reduced the friction of distance, the financial sector has its high degree of spatial agglomeration in particular

Received December 4, 2013, accepted December 18, 2013

Supported by National Natural Science Foundation of China (Grant No.71003004 and No.71373001)

Corresponding author: Hui BU, Assistant Professor, Tel: +86-10-82339123; E-mail: buhui@buaa.edu.cn. 
locations. Many financial institutions are focused on a particular city or region around the globe. These cities are often political, economic, culture, transportation and business centers for a country. Even with higher operating costs than other cities, these cities have attracted a large number of financial institutions being gathered here. Well, what is the reason for this phenomenon? Why is there spatial agglomeration of financial activities? This paper attempts to answer this question.

A financial center is conventionally regarded as a place with an agglomeration of financial institutions providing all banking and financial services, nationally or internationally. The development of financial centers can offer a good example to illustrate the continuous significance of geography in the location choice of businesses. $[1,2]$ explore that international financial centers have a particular set of location determinants by exemplifying the case of London. He also argues that the advantages of a given location as a financial center can be defined by the local characteristics and localized information jointly. $[3,4]$ suggest that the agglomeration process of financial services can be understood by assessing the importance of information hinterland and asymmetric information. [5] summarizes the state of arts of geography of money and finance, emphasizing the political economic approach in understanding the formation of geographies of money and finance. He agrees that, to a great extent, a wide range of social factors might contribute to the survival and success of international financial centers in particular places. [6] finds that financial services rely on information as an input and produce it as an output. Information is both the process and the product of financial services. [7, 8] assert that the friction of information flows across physical distance affects the location of financial activities, as information collection and verification are particularly crucial for financial business to play safe games.

$[9,10]$ argue that information problems have created the need for geographic agglomeration of financial activities based on the source of information. This is true even in an era when financial markets work through sophisticated telecommunication networks. Based on a survey of the actual location of multinational corporation (MNC) regional headquarters, and through investigation of reasons for the agglomeration of these headquarters, they anticipate that Beijing, as the prime source of policy information, is more likely than other Chinese cities to be the national pre-eminent financial center when the Chinese financial markets become more open to foreign firms in the near future. [11] finds significant agglomeration forces between financial intermediaries (downstream industry) on the one hand and business services and computer industry (upstream industries) on the other using macro data of Luxembourg services industry.

As the financial services industry is quite different from other industries, the traditional model of industrial agglomeration is not applicable for investigating finance agglomeration. This paper regards the financial services industry as a special kind of industry, and establishes a multi-region model, which reflects the characteristics of financial services industry.

The paper is organized as follows. The next section represents the basic multi-region model. Section 3 discusses a few numerical examples and considers the equilibrium of financial agglomeration. Section 4 investigates and explains the reasons and forces which determine the agglomeration by examining whether the equilibrium of financial agglomeration is sustainable. Conclusions are presented in Section 5. 


\section{The multi-region model}

A lot of researches have been done about the economics of trade and agglomeration. [12] presents a simple formal analysis which incorporates some important elements, such as economies of scale, the positive of product differentiation, and imperfect competition, and shows how it can be used to shed some light on these issues which cannot be handled in more conventional models. His model is derived from Dixit-Stiglitz's model ${ }^{[13]}$ of monopolistic competition. These issues include, in particular, the causes of trade between economies with similar factor endowments, and the role of a large domestic market in encouraging exports. He examines the effect of transportation costs, and shows that countries with larger domestic markets will, other things equal, have higher wage rates. He finds that countries will tend to export those goods for which they have relatively large domestic markets.

[14] develops a simple model that shows how a country can endogenously become differentiated into an industrialized "core" and an agricultural "periphery". In order to realize scale economies while minimizing transport costs, manufacturing firms tend to locate in the region with larger demand, but the location of demand itself depends on the distribution of manufacturing. Emergence of a core-periphery pattern depends on transportation costs, economies of scale, and the share of manufacturing in national income. [15] adopts an impressive number of simplifying assumptions in order to focus tightly on agglomeration forces created by pecuniary externalities.

Information is both the process and the product of financial services. As the potential opportunity and profitability of the financial sector depend much on the accessibility and reliability of information, the sizes as well as the features of information hinterland are key aspects that are attractive to the financial firms. Financial businesses need to collect, disseminate and interpret huge amounts of information. High-level financial firms, therefore, seek to locate within the information hinterland of an international city where information can be easily accessed and verified at lower costs.

By examining various forces behind the formation of a financial center, we argue that information problems have created the necessity of the geographic agglomeration of financial activities in the source of information even in the era when financial markets have worked through sophisticated telecommunication networks. So we assume that there will be opportunity costs caused by information asymmetry. That is to say, there will be costs caused by friction of information flows across physical distance. We consider an economy with two sectors, financial sector and real sector. There are two kinds of goods, financial products and real economy products. There are two kinds of resources, labor and capital.

\subsection{Assumption}

The model is based on the following assumptions:

1) Both the real sector and the financial sector provide a large variety of differentiated goods. They are both imperfectly competitive, having increasing returns.

2) Financial sector employs a single resource, labor, i.e. financial workers. Real economy sector consume two kinds of resources, labor and capital respectively. The product function of real sector industry is $Y=\Upsilon\left(L^{I}\right)^{a} K^{b}$, where $Y$ is the output, $\Upsilon$ is the technological coefficient, 
$L^{I}$ is the labor of real sector industry, $a$ is labor-output elasticity, $b$ is capital-output elasticity. We assume that each of these sector-specific factors is in fixed supply. The workers will move toward regions that offer high real wages and away from regions that offer below-average real wages.

3) The capital of the real sector will get larger through the flow of financial products.

4) Shipment of real sector products causes transportation costs. If one unit of a good is shipped from region $r$ to region $s$, only $1 / \tau_{r s}^{I}$ units arrive ${ }^{1}$. There are costs required to collect and verify the information of acceptable quality. So if a financial variety produced at location $r$ is sold at price $p_{r}$, then the relevant price of that variety at each consumption location $s$ is given by $p_{r s}=p_{r} \times \tau_{r s}$.

5) Every consumer shares the same Cobb-Douglas tastes for the two types of goods: $U=$ $F^{\mu} I^{1-\mu}$. Where $F$ represents a composite index of the consumption of financial goods, $I$ is a composite index of the consumption of the real economy good, and $\mu$ is a constant representing the expenditure share of financial goods. The quantity index $F$ is a utility function defined over a continuum of varieties of financial goods. The quantity index $I$ is a utility function defined over a continuum of varieties of real sector goods. We assume that $F$ and $I$ are defined by a constant-elasticity-of-substitution (CES) function respectively:

$$
F=\left[\sum_{i=1}^{n_{F}} d_{i}^{\rho}\right]^{1 / \rho}, \quad I=\left[\sum_{i=1}^{n_{I}} m_{i}^{\rho_{I}}\right]^{1 / \rho_{I}},
$$

where $d_{i}$ denotes the consumption of each available financial product variety; $m_{i}$ denotes the consumption of each available real sector product variety, $n_{F}$ and $n_{I}$ is the range of varieties produced respectively, often called the "number" of available varieties. In this specification, the parameter $\rho$ and $\rho_{I}$ represent the intensity of the preference for variety in financial goods and in real sector goods respectively. When they are close to 1 , differentiated goods are nearly perfect substitutes for each other; as they decrease towards 0 , the desire to consume a greater variety of financial and real sector goods increases.

6) The financial company will get average revenue of $\eta$ through selling one unit of product.

The description of the real sector refers to the assumptions of the models built by $[14,15]$ and etc.

\subsection{Consumer behavior}

Given income $y$ and a set of prices, $p_{i}^{I}$ for each real sector good and $p_{i}$ for each financial good, the consumer's problem is to maximize utility $U=F^{\mu} I^{1-\mu}$ subject to the budget constraint

$$
\sum_{i=1}^{n_{F}} p_{i} d_{i}+\sum_{i=1}^{n_{I}} p_{i}^{I} m_{i}=y
$$

We can see from the production function of the real sector industry $Y=\Upsilon\left(L^{I}\right)^{a} K^{b}$ that the output $Y$ will increase if the capital $K$ increases. And the flow of financial products will increase the capital of the real sector, and therefore increase the output of real sector. The increase of the output of real sector will reinforce the output of financial sector. Let the increasing ratios of the real sector and financial sector be $\beta_{1}, \beta_{2}$ respectively. Meanwhile, the income of consumers

\footnotetext{
${ }^{1}$ This idea comes from Samuelson $[16]$.
} 
will get larger at a certain ratio, and let it be $\beta_{3}$. So the budget constrain becomes

$$
\sum_{i=1}^{n_{F}} p_{i} \beta_{2} d_{i}+\sum_{i=1}^{n_{I}} p_{i}^{I} \beta_{1} m_{i}=\beta_{3} y
$$

and the value of $\beta_{3}$ is between the value of $\beta_{1}$ and the value of $\beta_{2}$.

First, whatever the value of the financial composite, each $d_{i}$ needs to be chosen so as to minimize the cost of attaining $F$. This means solving the following minimization problem:

$$
\begin{gathered}
\min \sum_{i=1}^{n_{F}} p_{i} d_{i} \\
\text { s.t. } F=\left[\sum_{i=1}^{n_{F}} d_{i}^{\rho}\right]^{1 / \rho}
\end{gathered}
$$

Denoting the price index for financial products by $G$ and setting $\rho=\frac{\sigma-1}{\sigma}$, we have

$$
G=\left(\sum_{i=1}^{n_{F}} p_{i}^{\frac{\rho}{\rho-1}}\right)^{\frac{\rho-1}{\rho}}=\left(\sum_{i=1}^{n_{F}} p_{i}^{1-\sigma}\right)^{\frac{1}{1-\sigma}}
$$

The price index measures the minimum cost of purchasing a unit of the composite index of financial goods. And $\sigma$ represents the elasticity of substitution between any two financial sector varieties and $\sigma>1$. Demand for $i^{\text {th }}$ variety of financial products $d_{i}$, can be written as

$$
d_{i}=\left(\frac{P_{i}}{G}\right)^{\frac{1}{\rho-1}} F=\left(\frac{P_{i}}{G}\right)^{-\sigma} F
$$

In the same way, denoting the price index for real sector products by $G^{I}$ and setting $\rho_{I}=$ $\frac{\sigma_{I}-1}{\sigma_{I}}$, we have

$$
G^{I}=\left(\sum_{i=1}^{n_{I}}\left(p_{i}^{I}\right)^{\frac{\rho_{I}}{\rho_{I}-1}}\right)^{\frac{\rho_{I}-1}{\rho_{I}}}=\left(\sum_{i=1}^{n_{I}}\left(p_{i}^{I}\right)^{1-\sigma_{I}}\right)^{\frac{1}{1-\sigma_{I}}}
$$

The price index measures the minimum cost of purchasing a unit of the composite index of real sector goods. And $\sigma_{I}$ represents the elasticity of substitution between any two real sector varieties and $\sigma_{I}>1$. Demand for $i^{t h}$ variety of real sector products $m_{i}$, can be written as

$$
m_{i}=\left(\frac{P_{i}^{I}}{G^{I}}\right)^{\frac{1}{\rho_{I}-1}} I=\left(\frac{P_{i}^{I}}{G^{I}}\right)^{-\sigma_{I}} I
$$

The next step of the consumer's problem is to divide total income between real sector and financial sector in aggregate, that is, to choose $F$ and $I$ so as to

$$
\begin{gathered}
\max U=\left(\beta_{2} F\right)^{\mu}\left(\beta_{1} I\right)^{1-\mu}=\beta_{2}^{\mu} \beta_{1}^{1-\mu} F^{\mu} I^{1-\mu} \\
\text { s.t. } \beta_{2} G F+\beta_{1} G^{I} I=\beta_{3} y
\end{gathered}
$$

which yields the results that

$$
F=\frac{\beta_{3} \mu y}{\beta_{2} G}, \quad I=\frac{\beta_{3}(1-\mu) y}{\beta_{1} G^{I}}
$$

Then, demand for each variety of financial products is

$$
d_{i}=\left(\frac{p_{i}}{G}\right)^{-\sigma} F=\left(\frac{p_{i}}{G}\right)^{-\sigma} \frac{\beta_{3} \mu y}{\beta_{2} G}=\beta_{3} \beta_{2}^{-1} \mu y \frac{p_{i}^{-\sigma}}{G^{1-\sigma}}
$$


Notice that, holding $G$ constant, the price elasticity of demand for every available financial sector variety is constant and equal to $\sigma$. We can now get the function of maximized utility:

$$
U=\beta_{3} \mu^{\mu}(1-\mu)^{1-\mu} y G^{-\mu}\left(G^{I}\right)^{\mu-1}
$$

\subsection{Multiple locations and opportunity costs caused by information asymmetry}

There are $R$ discrete locations. Assume that each variety is produced in only one location and that all varieties produced in a particular location are symmetric, having the same price. We denote the number of varieties produced in location $r$ by $n_{r}$. If a financial variety produced at location $r$ is sold at price $p_{r}$, then the relevant price of that variety at each consumption location $s$ is given by $p_{r s}=p_{r} \times \tau_{r s}$.

The financial price index may take a different value in each location; we denote this by writing the price index for location $s$ as $G_{s}$. The opportunity costs caused by information asymmetry together with the assumption that all varieties produced in a particular location have the same price mean that, using (4), the price index can be written as,

$$
G_{s}=\left[\sum_{r=1}^{R} n_{r}\left(p_{r} \tau_{r s}\right)^{1-\sigma}\right]^{1 /(1-\sigma)}, s=1,2, \cdots, R
$$

Consumption demand in location $s$ for a financial product produced in $r$ now follows as

$$
\beta_{3} \beta_{2}^{-1} \mu y_{s}\left(p_{r} \tau_{r s}\right)^{-\sigma} G_{s}^{\sigma-1}
$$

(from (8)), where $y_{s}$ is income for location $s$. Summing across locations in which the product is sold, the total sales of a single location $r$ variety, denoted $q_{r}$, therefore amount to:

$$
q_{r}=\beta_{3} \beta_{2}^{-1} \mu \sum_{r=1}^{R} y_{s}\left(p_{r} \tau_{r s}\right)^{-\sigma} G_{s}^{\sigma-1} \tau_{r s}
$$

\subsection{Producer behavior}

Next we turn to the production side of the economy. The financial and real sector good, we assume, are produced using an increasing-returns technology under conditions of imperfect competition. We assume them to involve economies of scale. These economies of scale arise at the level of the variety.

For the financial good, technology is the same for all varieties and in all locations and involves a fixed input of $A$ and marginal input requirement $c$. Thus, assuming that the only input is labor, the production of a quantity $q$ of any variety at any given location requires labor input $L$, given by $L=A+c q$.

Because of increasing returns to scale, consumers' preference for variety, and the unlimited number of potential varieties of financial goods, no firm will choose to produce the same variety supplied by another firm. This means that each variety is produced in only one location, by a single, specialized firm, so that the number of financial firms in operation is the same as the number of available varieties.

Next, consider a particular firm producing a specific variety at location $r$ and facing a given wage rate, $w_{r}$, for financial workers there. Since we know the financial company will get average revenue of $\eta$ through selling one unit of product, then with an original price $p_{r}$, its profit is given by

$$
B_{r}=\eta p_{r} q_{r}-w_{r}\left(A+c q_{r}\right)
$$


where $q_{r}$ is given by the demand function (11). Each firm is assumed to choose its price taking the price indices $G_{s}$ as given. The elasticity of demand is therefore $\sigma$, so profit maximization implies as follows for all varieties produced at $r^{[13]}$.

$$
\eta p_{r}\left(1-\frac{1}{\sigma}\right)=\eta p_{r} \rho=c w_{r}
$$

This is because that the profit maximization condition for each firm acting on its own is the familiar equality of marginal revenue and marginal cost.

We suppose that there is free entry and exit in response to profits or losses. Given the pricing rule, the profits of a firm at location $r$ are

$$
B_{r}=c w_{r} \frac{\sigma}{\sigma-1} q_{r}-w_{r}\left(A+c q_{r}\right)=w_{r}\left(\frac{c q_{r}}{\sigma-1}-A\right)
$$

Therefore, the zero-profit condition implies that the equilibrium output of any active firm is

$$
q^{*}=A(\sigma-1) / c,
$$

and the associated equilibrium labor input is $l^{*}=A+c q^{*}=A \sigma$.

Both $q^{*}$ and $l^{*}$ are constant common to every active firm in the economy. Therefore, if $L_{r}$ is the number of financial workers at location $r$, and $n_{r}$ is the number of financial firms and the number of the varieties produced at $r$, then $n_{r}=L_{r} / l^{*}=L_{r} /(A \sigma)$.

Notice that we are free to choose units of measurement for output. We choose units such that the marginal labor requirement satisfies the following equation $c=(\sigma-1) / \sigma=\rho$. We choose convenient units by setting the fixed input requirement $A$ to satisfy the following equation $A=\mu / \sigma$.

This normalization means that the pricing equation, the output level at which financial firms make no profit and the number of financial firms in each location become:

$$
\eta p_{r}=w_{r}, q^{*}=l^{*}=\mu, n_{r}=\frac{L_{r}}{\mu}
$$

For the real sector good, there are two kinds of inputs, labor and capital. We know that there is a ratio between labor and capital, so there is a ratio between the relevant using costs of capital and wages. Let the relevant using costs of capital $K$ be $H$. Let $H=\chi w_{r}^{I}$, where $\chi>0$. Next, consider a particular firm producing a specific variety at location $r$ and facing a given wage rate $w_{r}^{I}$, for real sector workers there. The price of a real sector product for location $r$ is $p_{r}^{I}$, the consume quantity of a real sector product for location $r$ is $q_{r}^{I}$. For the labor input, it involves a fixed input of $A^{I}$ and marginal input requirement $c_{I}$, so with an original price $p_{r}^{I}$, its profit is given by

$$
B_{r}^{I}=p_{r}^{I} q_{r}^{I}-w_{r}^{I}\left(A^{I}+c_{I} q_{r}^{I}\right)-H
$$

The elasticity of demand is therefore $\sigma_{I}$, so profit maximization implies ${ }^{[13]}$

$$
p_{r}^{I}\left(1-\frac{1}{\sigma_{I}}\right)=p_{r}^{I} \rho_{I}=c_{I} w_{r}^{I}
$$

So the profits of a firm at location $r$ are

$$
B_{r}^{I}=w_{r}^{I}\left(\frac{c_{I} q_{r}^{I}}{\sigma_{I}-1}-A^{I}-\chi\right)
$$


Therefore, the zero-profit condition implies that the equilibrium output of any active firm is

$$
q^{I^{*}}=\frac{\left(A^{I}+\chi\right)\left(\sigma_{I}-1\right)}{c_{I}},
$$

and the associated equilibrium labor input is

$$
l^{I^{*}}=A^{I}+c_{I} q^{I^{*}}=A^{I} \sigma_{I}+\chi\left(\sigma_{I}-1\right) .
$$

Therefore, if $L_{r}^{I}$ is the number of real sector workers at location $r$, and $n_{r}^{I}$ is the number of real sector firms and the number of the varieties produced at $r$, then $n_{r}^{I}=L_{r}^{I} / l^{I^{*}}$.

We can set $c_{I}=\rho_{I}$ and $A^{I}=(1-\mu) / \sigma_{I}-\chi \rho_{I}$. This normalization means that the pricing equation, the output level at which real sector firms make no profit and the number of real sector firms in each locations become:

$$
p_{r}^{I}=w_{r}^{I}, q^{I^{*}}=1-\mu+\chi, l^{I^{*}}=1-\mu, n_{r}^{I}=\frac{L_{r}^{I}}{1-\mu}
$$

\subsection{The financial wage equation}

We have seen that the condition that firms make no profits is equivalent to the condition that they produce $q^{*}$. Using the demand functions (11), we can get

$$
\left(p_{r}\right)^{\sigma}=\frac{\beta_{3} \beta_{2}^{-1} \mu}{q^{*}} \sum_{s=1}^{R} y_{s}\left(\tau_{r s}\right)^{1-\sigma} G_{s}^{\sigma-1}
$$

Using the equation (15), the nominal wage equation can be expressed as

$$
w_{r}=\eta\left[\sum_{s=1}^{R} \beta_{3} \beta_{2}^{-1} y_{s}\left(\tau_{r s}\right)^{1-\sigma} G_{s}^{\sigma-1}\right]^{1 / \sigma}
$$

Real income at each location is proportional to nominal income deflated by the cost-of-living index, which is $G_{r}^{\mu}\left(G_{r}^{I}\right)^{1-\mu}$. This means that the real wage of financial workers in location $r$, denoted $\omega_{r}$, is

$$
\omega_{r}=w_{r} G_{r}^{-\mu}\left(G_{r}^{I}\right)^{-(1-\mu)}
$$

\subsection{Instantaneous equilibrium}

Using equation (10) and (15), we can get the price index equations for location $r$

$$
G_{r}=\frac{1}{\eta}\left[\frac{1}{\mu} \sum_{s=1}^{R} L_{s}\left(w_{s} \tau_{s r}\right)^{1-\sigma}\right]^{1 /(1-\sigma)}
$$

In the same way, we can get the corresponding equations for the real sector ${ }^{2}$, the nominal wage equations can be expressed as

$$
w_{r}^{I}=\left[\sum_{s=1}^{R} \beta_{3} \beta_{1}^{-1} \frac{(1-\mu)}{(1-\mu+\chi)} y_{s}\left(\tau_{r s}^{I}\right)^{1-\sigma_{I}}\left(G_{s}^{I}\right)^{\sigma_{I}-1}\right]^{1 / \sigma_{I}}
$$

The corresponding real wage equation can be expressed as

$$
\omega_{r}^{I}=w_{r}^{I} G_{r}^{-\mu}\left(G_{r}^{I}\right)^{-(1-\mu)}
$$

\footnotetext{
${ }^{2}$ For the real sector, we add a superscript $I$ for each variable, and a subscript $I$ for each parameter. The meanings of them can refer to those explanations described for financial sector correspondingly.
} 
We can get the location $r$ 's price index equation for the real sector

$$
G_{r}^{I}=\left[\frac{1}{1-\mu} \sum_{s=1}^{R} L_{s}^{I}\left(w_{s}^{I} \tau_{s r}^{I}\right)^{1-\sigma_{I}}\right]^{1 /\left(1-\sigma_{I}\right)}
$$

At any point in time, we denote the share of region $r$ in the whole financial worker supply $L^{F}$ by $x_{r}$. We denote the share of region $r$ in the whole real sector worker supply $L^{I}$ by $\lambda$. It is convenient to choose units so that $L^{F}=\mu$ and $L^{I}=1-\mu$. Because there are $\mu$ financial workers and $1-\mu$ real sector workers in total, the income of region $r$ is:

$$
y_{r}=\mu x_{r} w_{r}+(1-\mu) \lambda_{r} w_{r}^{I}
$$

And the price index equations are:

$$
\begin{aligned}
& G_{r}=\frac{1}{\eta}\left[\sum_{s=1}^{R} x_{s}\left(w_{s} \tau_{s r}\right)^{1-\sigma}\right]^{1 /(1-\sigma)} \\
& G_{r}^{I}=\left[\sum_{s=1}^{R} \lambda_{s}\left(w_{s}^{I} \tau_{s r}^{I}\right)^{1-\sigma_{I}}\right]^{1 /\left(1-\sigma_{I}\right)}
\end{aligned}
$$

We find it most useful to think of that equilibrium as the simultaneous solution of these equations, which determine the income of each region, the respective price index of financial products and real sector products consumed in that region, the wage rate of workers in that region, and the real wage rate in that region.

This model's instantaneous equilibrium can be thought of as determined by the simultaneous solution of the wage equations (20) and (23), the real wage equations (21) and (24), the equations for income (26), and the equations for price indices (27) and (28).

Consider a two-location version of these equations. Writing the equations out in full, we have the price indices for the financial sector ${ }^{3}$ :

$$
\begin{aligned}
& G_{1}=\frac{1}{\eta}\left[x w_{1}^{1-\sigma}+(1-x)\left(w_{2} \tau_{2}\right)^{1-\sigma}\right]^{1 /(1-\sigma)} \\
& G_{2}=\frac{1}{\eta}\left[x\left(w_{1} \tau_{1}\right)^{1-\sigma}+(1-x) w_{2}^{1-\sigma}\right]^{1 /(1-\sigma)}
\end{aligned}
$$

The wage equations for the financial sector:

$$
\begin{gathered}
w_{1}=\eta\left[\beta_{3} \beta_{2}^{-1} y_{1} G_{1}^{\sigma-1}+\beta_{3} \beta_{2}^{-1} y_{2} \tau_{1}^{1-\sigma} G_{2}^{\sigma-1}\right]^{1 / \sigma} \\
w_{2}=\eta\left[\beta_{3} \beta_{2}^{-1} y_{1} \tau_{2}^{1-\sigma} G_{1}^{\sigma-1}+\beta_{3} \beta_{2}^{-1} y_{2} G_{2}^{\sigma-1}\right]^{1 / \sigma} \\
\omega_{1}=w_{1} G_{1}^{-\mu}\left(G_{1}^{I}\right)^{-(1-\mu)} \\
\omega_{2}=w_{2} G_{2}^{-\mu}\left(G_{2}^{I}\right)^{-(1-\mu)}
\end{gathered}
$$

The price indices for the real sector:

$$
\begin{aligned}
& G_{1}^{I}=\left[\lambda\left(w_{1}^{I}\right)^{1-\sigma_{I}}+(1-\lambda)\left(w_{2}^{I} \tau\right)^{1-\sigma_{I}}\right]^{1 /\left(1-\sigma_{I}\right)} \\
& G_{2}^{I}=\left[\lambda\left(w_{1}^{I} \tau\right)^{1-\sigma_{I}}+(1-\lambda)\left(w_{2}^{I}\right)^{1-\sigma_{I}}\right]^{1 /\left(1-\sigma_{I}\right)}
\end{aligned}
$$

\footnotetext{
${ }^{3}$ To be simplified, if a financial variety produced at location 1 is sold at price $p_{1}$, then the relevant price of that variety at location 2 is given by $p_{12}=p_{1} \times \tau_{1}$; if a financial variety produced at location 1 is sold at price $p_{2}$, then the relevant price of that variety at location 1 is given by $p_{21}=p_{2} \times \tau_{2}$.
} 
The wage equations for the real sector:

$$
\begin{gathered}
w_{1}^{I}=\left[\beta_{3} \beta_{1}^{-1} \frac{(1-\mu)}{(1-\mu+\chi)} y_{1}\left(G_{1}^{I}\right)^{\sigma_{I}-1}+\beta_{3} \beta_{1}^{-1} \frac{(1-\mu)}{(1-\mu+\chi)} y_{2} \tau^{1-\sigma_{I}}\left(G_{2}^{I}\right)^{\sigma_{I}-1}\right]^{1 / \sigma_{I}} \\
w_{2}^{I}=\left[\beta_{3} \beta_{1}^{-1} \frac{(1-\mu)}{(1-\mu+\chi)} y_{1} \tau^{1-\sigma_{I}}\left(G_{1}^{I}\right)^{\sigma_{I}-1}+\beta_{3} \beta_{1}^{-1} \frac{(1-\mu)}{(1-\mu+\chi)} y_{2}\left(G_{2}^{I}\right)^{\sigma_{I}-1}\right]^{1 / \sigma_{I}} \\
\omega_{1}^{I}=w_{1}^{I} G_{1}^{-\mu}\left(G_{1}^{I}\right)^{-(1-\mu)} \\
\omega_{2}^{I}=w_{2}^{I} G_{2}^{-\mu}\left(G_{2}^{I}\right)^{-(1-\mu)}
\end{gathered}
$$

The equations for income become:

$$
\begin{gathered}
y_{1}=\mu x w_{1}+(1-\mu) \lambda w_{1}^{I} \\
y_{2}=\mu(1-x) w_{2}+(1-\mu)(1-\lambda) w_{2}^{I}
\end{gathered}
$$

This two-region model's instantaneous equilibrium can be thought of as determined by the simultaneous solution of the wage equations (29) to (42).

\section{Numerical examples}

In order to focus on the analysis of financial sector, we use the wage rate of the real sector as the numeraire and assume that real sector workers have the same wage rate in all regions. So we can get $w_{1}^{I}=w_{2}^{I}$ and $G_{1}^{I}=G_{2}^{I}=1$. The real wage equations (33) and (34) become

$$
\omega_{1}=w_{1} G_{1}^{-\mu} ; \quad \omega_{2}=w_{2} G_{2}^{-\mu}
$$

The income equations (41) and (42) become

$$
y_{1}=\mu x w_{1}+(1-\mu) \lambda ; \quad y_{2}=\mu(1-x) w_{2}+(1-\mu)(1-\lambda)
$$

So the model's simplified instantaneous equilibrium can be thought of as determined by the simultaneous solution of the equations (29), (30), (31), (32), (43) and (44).

It is very helpful to look first at some numerical examples. The workers will move toward regions that offer high real wages and away from regions that offer below-average real wages. We can ask whether $\omega_{2}$ is greater or less than $\omega_{1}$ to judge the migration choices of workers. If $\omega_{2} \leq \omega_{1}$ satisfies, then financial workers will not move out of region 1; if $\omega_{2}>\omega_{1}$ satisfies, then financial workers will move out of region 1. So panel (a), (b) and (c) of figure 1 plot $\omega_{1}-\omega_{2}$, the difference between the two regions' real wage rates in financial sector, against $x$, the region 1 share of financial activities. We can get considerable insight by examining an obvious special case: that of a two-region economy in which real sector is evenly divided between regions. So we get $\lambda=1 / 2$. All three figures are calculated for $\sigma=5, \mu=0.3$. However, the opportunity costs caused by information asymmetry is different in each: panel (a) of figure 1 shows a high opportunity costs case, $\tau_{1}=\tau_{2}=1.5$, panel (b) of figure 1 a low case, $\tau_{1}=\tau_{2}=1.4$, and panel (c) of figure 1 an intermediate case, $\tau_{1}=\tau_{2}=1.45$.

In panel (a) of Figure1, the wage difference is positive if $x$ is less than 0.5 , negative if $x$ is greater than 0.5. This means that if a region has more than half the financial labor force, it is less attractive to workers than the other region. Clearly, in this case the economy converges to 
a long-run symmetric equilibrium in which financial firms is equally divided between the two regions.

In panel (b) of Figure1, by contrast, the wage difference slopes strictly upward in $x$ : the higher the share of financial firms in either region, the more attractive the region becomes. Other things equal, a larger financial labor force makes a region more attractive both because the larger local market leads to higher nominal wages and because the larger variety of locally produced goods lowers the price index. The important point here is that although an equal division of financial activities between the two regions is still an equilibrium, it is now unstable: if one region should have even a slightly larger financial sector, that sector would tend to grow over time while the other region's financial sector shrank, leading eventually to a pattern with all financial activities concentrated in one region.
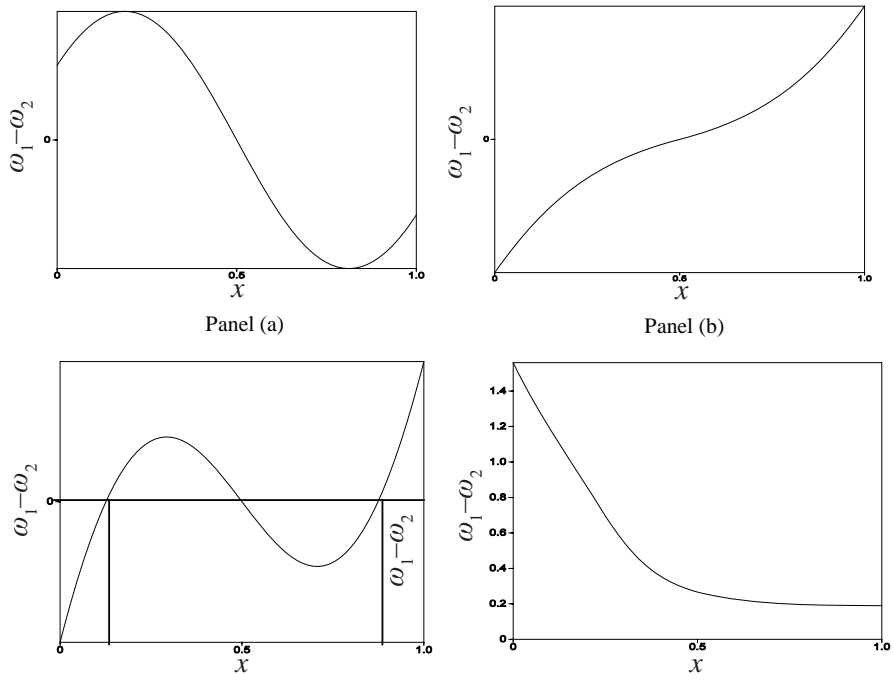

Panel (c)

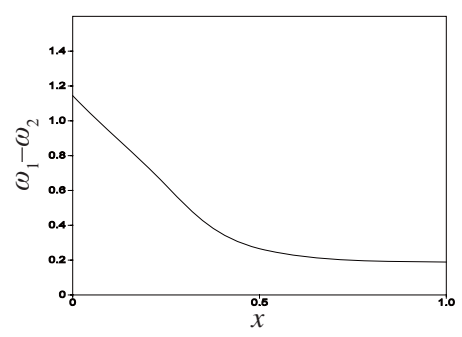

Panel (d)

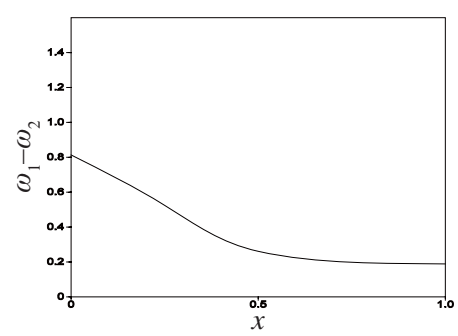

Panel (e)

Panel (f)
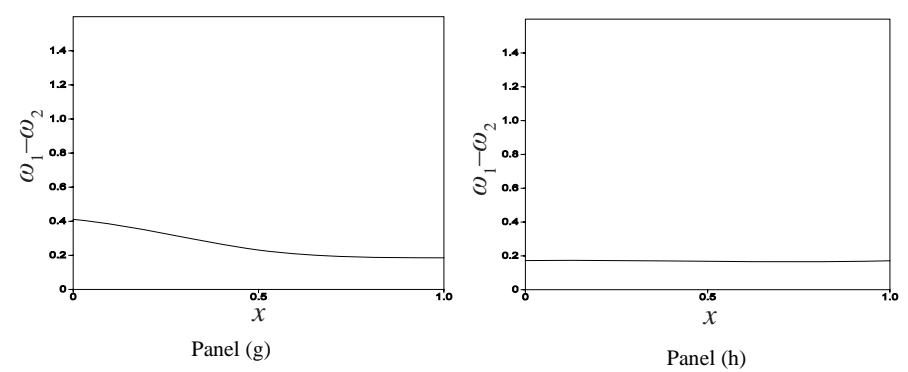

Figure 1 Real wage differences 
Finally, panel (c) of Figure1, for an intermediate level of opportunity costs caused by information asymmetry, shows a more complicated picture. The symmetric equilibrium is now locally stable, as in panel (a) of Figure1. However, two unstable equilibriums now flank it: if $x$ starts from either a sufficiently high or a sufficiently low initial value, the economy converges not to the symmetric equilibrium but to a pattern with all financial activities in only one region. This picture then has five equilibriums: three unstable (the symmetric equilibrium and financial activities concentration in either region) and two unstable.

From these three cases it is straightforward to understand how the types of equilibriums vary with opportunity costs caused by information asymmetry. At sufficiently high opportunity costs, there is a unique stable equilibrium in which financial activities are evenly divided between the regions. When opportunity costs caused by information asymmetry fall below some critical level, new stable equilibrium emerge in which all financial activity is concentrated in one region. When they fall below a second critical level, the symmetric equilibrium becomes unstable.

If the two regions have different amount of financial information, there will exist an information hinterland. So we suppose $\tau_{1}<\tau_{2}$, then region 1 is the information hinterland.

We can get considerable insight by examining an obvious special case: there are no costs required to collect and verify the information from region 1 . That is to say, the relevant price of a financial variety produced in location 1 at consumption location 2 will remain the same. So we can get $\tau_{1}=1$. Panel (d) of Figure 1 shows a high opportunity costs of region 2 case, $\tau_{2}=10$, panel (e) of Figure 1 a lower case, $\tau_{2}=7$, and panel (f) of Figure 1 an intermediate case, $\tau_{2}=5$, panel (g) of Figure 1 a low case, $\tau_{2}=3$, panel (h) of Figure 1 a lower case, $\tau_{2}=2$. These figures show that $\omega_{1}-\omega_{2}$ is always positive, and so the equilibrium of a core-periphery pattern with all financial activities concentrated in region 1 is stable.

\section{Equilibrium and sustainability of finance agglomeration}

Suppose we start with all financial firms concentrated in one region, say region 1 . To determine whether this is a stable equilibrium, we ask whether a small group of workers moving from region 1 to region 2 would receive a higher real wage than that received by the workers remaining behind. If so, a core-periphery pattern is not a stable equilibrium: financial firms will shift over time to the peripheral region. If not, a core-periphery pattern is a stable equilibrium. The concentration of financial activities will be self-sustaining. In fact, finance agglomeration and real sector industry agglomeration will influence each other. In order to capture these characteristic, we suppose all real sector firms concentrated in one region, say region 2.

In short, to assess whether a core-periphery pattern is sustainable, we need to posit a situation in which $x=1 ; \lambda=0$, and ask whether in that case $\omega_{2}$ is greater or less than $\omega_{1}$. If we can get $\omega_{2} \leq \omega_{1}$, then the core-periphery pattern is sustainable, because financial workers will not move out of region 1 .

Suppose we set $x=1 ; \lambda=0$. Simply guess that $w_{1}=1, w_{2}^{I}=1 ; \eta=1, \tau_{2}=\alpha \tau_{1}$; in that case, we can get

$$
\begin{gathered}
G_{1}=\frac{1}{\eta}\left[x w_{1}^{1-\sigma}+(1-x)\left(w_{2} \tau_{2}\right)^{1-\sigma}\right]^{1 /(1-\sigma)}=w_{1}=1 \\
G_{2}=\frac{1}{\eta}\left[x\left(w_{1} \tau_{1}\right)^{1-\sigma}+(1-x)\left(w_{2}\right)^{1-\sigma}\right]^{1 /(1-\sigma)}=\tau_{1}
\end{gathered}
$$




$$
\begin{gathered}
G_{1}^{I}=\left[\lambda\left(w_{1}^{I}\right)^{1-\sigma_{I}}+(1-\lambda)\left(w_{2}^{I} \tau\right)^{1-\sigma_{I}}\right]^{1 /\left(1-\sigma_{I}\right)}=\tau \\
G_{2}^{I}=\left[\lambda\left(w_{1}^{I} \tau\right)^{1-\sigma_{I}}+(1-\lambda)\left(w_{2}^{I}\right)^{1-\sigma_{I}}\right]^{1 /\left(1-\sigma_{I}\right)}=w_{2}^{I}=1 \\
y_{1}=\mu x w_{1}+(1-\mu) \lambda w_{1}^{I}=\mu \\
y_{2}=\mu(1-x) w_{2}+(1-\mu)(1-\lambda) w_{2}^{I}=1-\mu
\end{gathered}
$$

And notice that the financial price index is higher in 2 than in 1 , because location 2 has to import all its financial products. The real sector price index is higher in 1 than in 2 , because location 1 has to import all its real sector products. Notice that whether the income is higher in location 1 than in location 2 depends on the share of the financial activities in the economy.

Because $w_{1}=1, G_{1}=1, G_{1}^{I}=\tau$ satisfies, it then follows that $\omega_{1}=w_{1} G_{1}^{-\mu}\left(G_{1}^{I}\right)^{-(1-\mu)}=$ $\tau^{\mu-1}$ as well. So we all need to do is determine $\omega_{2}$, and see whether it is more or less than $\tau^{\mu-1}$. That is to say, determine whether $\omega_{2} \tau^{1-\mu}$ is more or less than 1 . Substituting into the nominal and real wage equations (32) and (34), we have $\omega_{2} \tau^{1-\mu}=\tau_{1}^{-\mu} \tau^{1-\mu}\left[\mu \tau_{2}^{1-\sigma}+(1-\mu) \tau_{1}^{\sigma-1}\right]^{1 / \sigma}$.

It is helpful to rewrite it, in the form

$$
J=\omega_{2}^{\sigma} \tau^{\sigma(1-\mu)}=\mu \alpha^{1-\sigma} \tau_{1}^{1-\sigma-\sigma \mu} \tau^{\sigma(1-\mu)}+(1-\mu) \tau_{1}^{\sigma-1-\sigma \mu} \tau^{\sigma(1-\mu)}
$$

where $\sigma>1, \tau_{1}>1, \tau>1,0<\mu<1$.

Proposition 1 Clearly, when $\tau_{1}=\tau_{2}=1, \tau=1$ (no costs related with space), $\omega_{2} \tau^{1-\mu}=$ 1. Location is irrelevant.

When $\tau_{1}=\tau_{2}=1, \tau=1$, it means that there are no transport costs for real sector products' shipment, and there are no opportunity costs caused by information asymmetry for financial sector. In fact, many scholars believe that the economic role of space is increasingly insignificant. [17] asserts that, with sophisticated networks of electronic communications and electronic money, the circulation of capital is no longer obstructed by distance. [18, 19] and [20] argue that the power of globalization has overridden the sovereignty and autonomy of nation-states, making the economic space of a country meaningless.

Proposition 2 If the region where the financial firms located in is an information hinterland for financial activities, the financial agglomeration will sustain.

If region 1 is an information hinterland for financial activities, the valuable financial information flows with little cost. We can conclude $\tau_{1}=1$. When there are no transport costs for real sector, i.e. $\tau=1$, we can get $J=\mu \alpha^{1-\sigma}+(1-\mu)<1$. [3, 4] suggest that the agglomeration process of financial services can be understood by assessing the importance of information hinterland and asymmetric information.

Proposition 3 If there are transport costs for real sector products' shipment, and there are no opportunity costs caused by information asymmetry for financial sector, the financial firms tend to move into the region where real sector agglomeration has happened.

When $\tau_{1}=1, \tau>1, \alpha=1$, using equation (51), we can get $J=\tau^{\sigma(1-\mu)}>1$. This is because that the financial institutes tend to concentrate near their major clients in order to serve them better. 
Proposition 4 If region 1 is an information hinterland for financial activities, and there are transport costs for real sector products' shipment, there exists a critical point $\alpha^{*}$. If $\alpha>\alpha^{*}$, the financial agglomeration will sustain; if $\alpha<\alpha^{*}$, the financial agglomeration will not sustain.

When $\tau_{1}=1, \tau>1, \alpha>1$ satisfies, we can get

$$
J=\tau^{\sigma(1-\mu)}\left[\mu \alpha^{1-\sigma}+(1-\mu)\right] .
$$

If we set

$$
\alpha^{*}=\left[\frac{\tau^{\sigma(\mu-1)}-(1-\mu)}{\mu}\right]^{1 /(1-\sigma)},
$$

we can find that when $\alpha=\alpha^{*}$ satisfies, $J=1$ can be derived. And similarly, when $\alpha<\alpha^{*}$ satisfies, $J>1$ can be derived; when $\alpha>\alpha^{*}$ satisfies, $J<1$ can be derived. That is why we get this proposition. Economic geography has long recognized that the location of economic activities in general and financial businesses in particular represents the outcome between centripetal and centrifugal forces ${ }^{[2,4,7,14]}$. Real sector transportation costs seem clearly to be a centrifugal force against financial agglomeration. Also, financial services rely on information as an input and produce it as an output. Information is both the process and the product of financial services ${ }^{[6]}$. The ways in which information has been generated and interpreted is significant to the viability of the financial institutions. So the size and features of information hinterland are key aspects that are attractive to the financial firms, which are centripetal forces for financial agglomeration.

Proposition 5 If $\rho<\mu$ satisfies, the agglomeration forces are so strong that a coreperiphery pattern is always an equilibrium.

When $\tau_{1}$ does not tend to infinity, using equation (51), we can get the derivative of $\tau_{1}$ :

$$
\frac{\mathrm{d} J}{\mathrm{~d} \tau_{1}}=\mu \alpha^{1-\sigma}(1-\sigma-\sigma \mu) \tau_{1}^{-\sigma(1+\mu)} \tau^{\sigma(1-\mu)}+(1-\mu)(\sigma-1-\sigma \mu) \tau_{1}^{\sigma-2-\sigma \mu} \tau^{\sigma(1-\mu)}
$$

Clearly, if $\sigma-1-\sigma \mu<0$ satisfies, we can get

$$
\frac{\mathrm{d} J}{\mathrm{~d} \tau_{1}}<0
$$

In fact, when $\tau_{1} \rightarrow+\infty$,

$$
\lim _{\tau_{1} \rightarrow+\infty} \frac{\tau_{1}^{1-\sigma-\sigma \mu}}{\tau_{1}^{\sigma-1-\sigma \mu}}=\lim _{\tau_{1} \rightarrow+\infty} \tau_{1}^{-2(\sigma-1)}=0 .
$$

So $\tau_{1}^{1-\sigma-\sigma \mu}$ is the infinitesimal of higher order of $\tau_{1}^{\sigma-1-\sigma \mu}$. So when $\tau_{1} \rightarrow+\infty$, we can derive that

$$
J=\omega_{2}^{\sigma} \tau^{(1-\mu) \sigma}=(1-\mu) \tau_{1}^{\sigma-1-\sigma \mu} \tau^{\sigma(1-\mu)}
$$

and

$$
\frac{\mathrm{d} J}{\mathrm{~d} \tau_{1}}=(1-\mu)(\sigma-1-\sigma \mu) \tau_{1}^{\sigma-2-\sigma \mu} \tau^{\sigma(1-\mu)} .
$$

Clearly, if $\sigma-1-\sigma \mu<0$, we can get $\frac{\mathrm{d} J}{\mathrm{~d} \tau_{1}}<0$. Because we have already set $\rho=\frac{\sigma-1}{\sigma}, \sigma-1-\sigma \mu<0$ equals to $\rho<\mu$. So we get the conclusion.

The parameter $\rho$ represents the intensity of the preference for variety in financial goods. We see that as $\rho$ decreases toward 0 , the desire to consume a greater variety of financial goods 
increases. The parameter $\mu$ is a constant representing the expenditure share of financial goods. If $\rho<\mu$, the increasing returns are so strong that forces working toward agglomeration always prevail in such economies.

Proposition 6 There is a critical point $\tau^{*}$, if $\tau_{1}<\tau^{*}$, the financial agglomeration is sustainable; if $\tau_{1}>\tau^{*}$, the financial agglomeration is not sustainable.
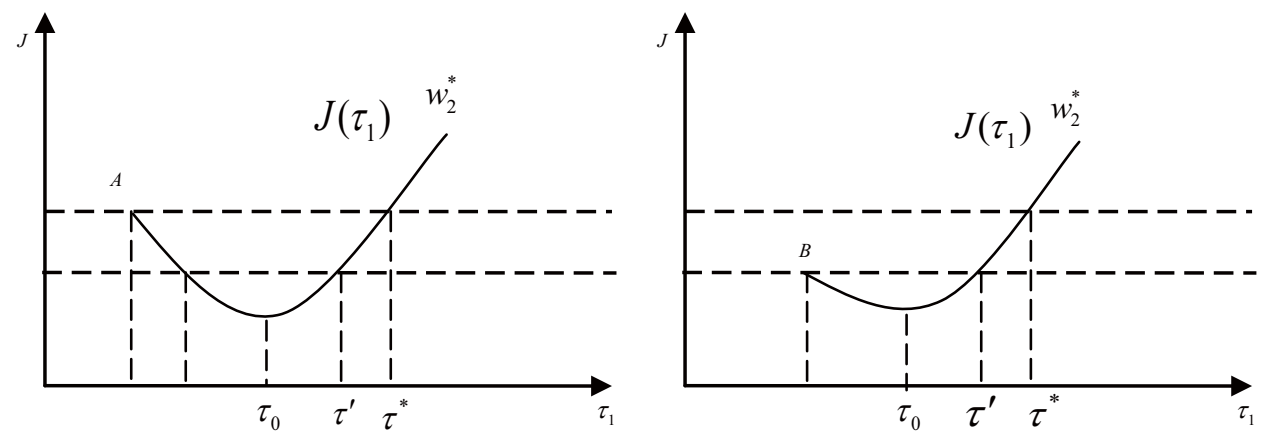

Figure 2 Sustain point of financial agglomeration

When $\rho>\mu$, we can get

$$
\lim _{\tau_{1} \rightarrow 0^{+}} J\left(\tau_{1}\right)=+\infty, \lim _{\tau_{1} \rightarrow+\infty} J\left(\tau_{1}\right)=+\infty .
$$

So figure 2 shows the curve of $J\left(\tau_{1}\right)$. There is a minimum point of $J\left(\tau_{1}\right)$.

When $\tau_{1}=1$, using equation (52) we can get

$$
\frac{\mathrm{d} J}{\mathrm{~d} \tau_{1}}=\mu \alpha^{1-\sigma}(1-\sigma-\sigma \mu) \tau^{\sigma(1-\mu)}+(1-\mu)(\sigma-1-\sigma \mu) \tau^{\sigma(1-\mu)} .
$$

When $\tau_{2}=1, \alpha=1$, we get

$$
\frac{\mathrm{d} J}{\mathrm{~d} \tau_{1}}=-\tau^{\sigma(1-\mu)} \sigma \mu+\tau^{\sigma(1-\mu)}(1-\sigma)(2 \mu-1) .
$$

If $|\sigma \mu|<|(1-\sigma)(2 \mu-1)|$ satisfies, we know that

$$
\frac{\mathrm{d} J}{\mathrm{~d} \tau_{1}}>0
$$

So $\tau_{0}$ lies on the left side of $\tau_{1}=1$. So we can get a critical point $\tau_{1}=\tau^{*}$. When $\tau_{1}<\tau^{*}$, we get $\omega_{2} \tau^{1-\mu}<1$ and when $\tau_{1}>\tau^{*}$, we get $\omega_{2} \tau^{1-\mu}>1$.

If $|\sigma \mu|>|(1-\sigma)(2 \mu-1)|$ satisfies, we know that

$$
\frac{\mathrm{d} J}{\mathrm{~d} \tau_{1}}<0 .
$$

So $\tau_{0}$ lies on the right side of $\tau_{1}=1$. So we can get a critical point $\tau_{1}=\tau^{*}$. When $\tau_{1}<\tau^{*}$, we get $\omega_{2} \tau^{1-\mu}<1$ and when $\tau_{1}>\tau^{*}$, we get $\omega_{2} \tau^{1-\mu}>1$.

If $|\sigma \mu|=|(1-\sigma)(2 \mu-1)|$ satisfies, we know that

$$
\frac{\mathrm{d} J}{\mathrm{~d} \tau_{1}}=0 .
$$

So $\tau_{1}=1$ is the minimum point of $J\left(\tau_{1}\right)$. So we can get a critical point $\tau_{1}=\tau^{*}$. When $\tau_{1}<\tau^{*}$, we get $\omega_{2} \tau^{1-\mu}<1$ and when $\tau_{1}>\tau^{*}$, we get $\omega_{2} \tau^{1-\mu}>1$. 
When $\tau_{2}>1, \alpha>1$ satisfies, we can get the following results:

If

$$
\alpha^{1-\sigma}>\frac{(\mu-1)(\sigma-1-\sigma \mu)}{\mu(1-\sigma-\sigma \mu)}
$$

satisfies, we know that

$$
\frac{\mathrm{d} J}{\mathrm{~d} \tau_{1}}<0
$$

So $\tau_{0}$ lies on the right side of $\tau_{1}=1$. So we can get a critical point $\tau_{1}=\tau^{*}$. When $\tau_{1}<\tau^{*}$, we get $\omega_{2} \tau^{1-\mu}<1$ and when $\tau_{1}>\tau^{*}$, we get $\omega_{2} \tau^{1-\mu}>1$.

If

$$
\alpha^{1-\sigma}=\frac{(\mu-1)(\sigma-1-\sigma \mu)}{\mu(1-\sigma-\sigma \mu)}
$$

satisfies, we know that

$$
\frac{\mathrm{d} J}{\mathrm{~d} \tau_{1}}=0
$$

So $\tau_{1}=1$ is the minimum point of $J\left(\tau_{1}\right)$. So we can get a critical point $\tau_{1}=\tau^{*}$. When $\tau_{1}<\tau^{*}$, we get $\omega_{2} \tau^{1-\mu}<1$ and when $\tau_{1}>\tau^{*}$, we get $\omega_{2} \tau^{1-\mu}>1$.

If

$$
\alpha^{1-\sigma}<\frac{(\mu-1)(\sigma-1-\sigma \mu)}{\mu(1-\sigma-\sigma \mu)}
$$

satisfies, we know that

$$
\frac{\mathrm{d} J}{\mathrm{~d} \tau_{1}}>0 .
$$

So $\tau_{0}$ lies on the left side of $\tau_{1}=1$. So we can get a critical point $\tau_{1}=\tau^{*}$. When $\tau_{1}<\tau^{*}$, we get $\omega_{2} \tau^{1-\mu}<1$ and when $\tau_{1}>\tau^{*}$, we get $\omega_{2} \tau^{1-\mu}>1$.

To sum up, we can get the conclusion of Proposition 6. The conclusion of Proposition 6 is the same with the results of numerical examples. This explains why there isn't one specific financial center throughout the world. Because there is a sustain point for the financial agglomeration. If the costs caused by the space are too high, the financial activities will find a new place to locate.

Proposition 7 The bigger the economies of scale of the financial activities are, the stronger the agglomeration forces are.

For equation (52), if $\sigma \rightarrow 1^{+}$, we can get $\lim _{\sigma \rightarrow 1^{+}}(\sigma-1-\sigma \mu)=-\mu<0$. So we can derive that $\frac{\mathrm{d} J}{\mathrm{~d} \tau_{1}}<0$. Regard $J$ as a function of $\sigma$, and we can get:

$$
\lim _{\sigma \rightarrow 1} J(\sigma)=\tau^{1-\mu} \tau_{1}^{-\mu}
$$

If $\tau=1$ satisfies, we can get $J \rightarrow \tau_{1}^{-\mu}<1$ when $\sigma \rightarrow 1$. So we can get Proposition 7 . The parameter $\sigma$ represents the elasticity of substitution between any two varieties. The lower is $\sigma$, the more differentiated are product varieties. The bigger the economies of scale of the financial activities are, the stronger the agglomeration forces are.

Proposition 8 If the share of financial goods is large, the financial agglomeration is sustainable. 
When $\tau=1$ and regard $J$ as a function of $\mu$, we can get

$$
\frac{\mathrm{d} J}{\mathrm{~d} \mu}=\left(\tau_{2}^{1-\sigma} \tau_{1}^{-\sigma \mu}-\tau_{1}^{\sigma-1-\sigma \mu}\right)-\sigma\left[\mu \tau_{2}^{1-\sigma} \tau_{1}^{-\sigma \mu}+(1-\mu) \tau_{1}^{\sigma-1-\sigma \mu}\right] \ln \tau_{1}
$$

After a few calculations, we can get $\frac{\mathrm{d} J}{\mathrm{~d} \mu}<0$. When $\mu=0$, we can get $\omega_{2}=\left(\tau_{1}^{\sigma-1}\right)^{1 / \sigma}>1$ because of $\tau_{1}>1$. When $\mu=1$, we can get $\omega_{2}=\left(\tau_{2}^{1-\sigma} \tau_{1}^{-\sigma}\right)^{1 / \sigma}<1$ because of $\sigma>1$. The curve of $\omega_{2}$ is shown by Figure 3 .

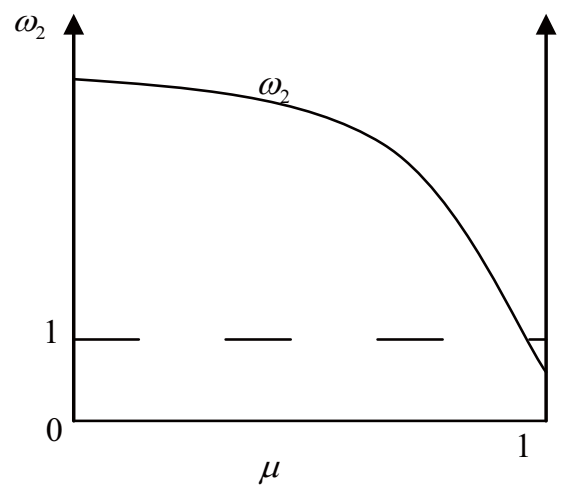

Figure 3 Curve of $\omega_{2}$

Proposition 9 If there are a lot of non-standardized financial information in one region, the financial agglomeration in that region is sustainable.

Regard $J$ as a function of $\alpha$, and we can get

$$
\frac{\mathrm{d} J}{\mathrm{~d} \alpha}=\mu \tau^{\sigma(1-\mu)} \tau_{1}^{1-\sigma-\sigma \mu}(1-\sigma) \alpha^{-\sigma}
$$

From equation (55), we can get $\frac{\mathrm{d} J}{\mathrm{~d} \alpha}<0$. So the bigger $\alpha$ is, the more sustainable the equilibrium of financial agglomeration is.

We can see that the conclusions accord with the results of numerical examples. In fact, [3] has focused on two information concepts for their effect on the development of a financial center: information hinterland and information asymmetry. The information hinterland is defined as the region for which a particular core city, acting as that regional center, provides the best access point for the profitable exploitation of valuable information flows. It can be measured by the patterns of information flow, although the measurement is practically difficult due to data limitations. In our model, we think that $\alpha$ can be regarded as a measure of whether the central area is an information center.

Within the information hinterland, valuable information flows first and with least cost. Information users who are much closer to the heart of information hinterland are therefore able to act on earlier at lower costs, than those far from the source of information. The value of information is a function of the social and economic characteristics of the hinterland center. As the potential opportunity and profitability of the financial sector depend much on the accessibility and reliability of information, the size and features of information hinterland are key aspects that are attractive to the financial firms. An important financial center tends to develop in a politically and economically influential city with a strong information hinterland, in terms of both information quantity and information quality. 
Proposition 10 The agglomeration of real sector industry will enhance the agglomeration of finance.

If $x=1, \lambda=0$, we don't set the financial wage rate of region 1 and the real sector wage rate of region 2 . We can get

$$
\omega_{2}=w_{2} G_{2}^{-\mu}\left(G_{2}^{I}\right)^{-(1-\mu)}=\eta\left[\beta_{3} \beta_{2}^{-1} y_{1} \tau_{2}^{1-\sigma} G_{1}^{\sigma-1}+\beta_{3} \beta_{2}^{-1} y_{2} G_{2}^{\sigma-1}\right]^{1 / \sigma} G_{2}^{-\mu}\left(G_{2}^{I}\right)^{-(1-\mu)} .
$$

So we can get that

$$
\frac{\mathrm{d} \omega_{2}}{\mathrm{~d}\left(\beta_{3} \beta_{2}^{-1}\right)}>0
$$

It means $\omega_{2}$ will increase if $\beta_{3} \beta_{2}^{-1}$ increases. In fact, $\beta_{3} \beta_{2}^{-1}$ represents the reinforcement relationship between the financial sector and real sector. It means that if the reinforcing effects between the financial sector and real sector are strong, the agglomeration of finance will tend to locate in where the agglomeration of real sector industry located.

If we suppose all financial firms and real sector firms concentrated in region 1. It means that $x=1, \lambda=1$. Next, we have to determine whether this is a stable equilibrium. In fact, we get the results:

$$
\omega_{2}=w_{2} G_{2}^{-\mu}\left(G_{2}^{I}\right)^{-(1-\mu)}=\left(\tau_{2}^{1-\sigma}\right)^{1 / \sigma} \tau_{1}^{-\mu} \tau^{\mu-1} ; J=\omega_{2}^{\sigma}=\alpha^{1-\sigma} \tau_{1}^{1-\sigma-\sigma \mu} \tau^{-\sigma(1-\mu)}
$$

We can derive that $\frac{\mathrm{d} J}{\mathrm{~d} \tau}<0$, so we know $J(\tau)$ is a strictly monotone decreasing function and $J<1$. To sum up, we can get the conclusion of Proposition 10 .

[4] argues that obviously, financial sector agglomeration reflects and reinforces real sector agglomeration. And inversely, real sector agglomeration reflects and reinforces financial sector agglomeration. So the financial firms tend to locate where there is already real sector agglomeration.

\section{Conclusions}

Through this analytical model, this paper discusses the formation mechanism and equilibrium of finance agglomeration. Our findings suggest that emergence of a core-periphery pattern of finance agglomeration depends on opportunity costs caused by information asymmetry, economies of scale, the share of financial services industry in the economy and the amount of financial information. And the agglomeration of real sector industry will enhance the agglomeration of finance. Finally, this paper puts forward a ratio, which is related with the opportunity costs, could be regarded as a measure of whether the central area is an information center.

Currently, China has prioritized Shanghai to be the top financial center in the country. Many incentive policies have been introduced to promote the financial sector there. Shanghai has achieved remarkable social and economic transformation in the past decade. We suggest that Shanghai should improve the sophistication in information technologies, so that standardized information can be obtained over greater distances without much cost. In this way, there will be less opportunity costs for the periphery locations to consume the financial products in Shanghai. However, at the same time Shanghai should be the source of information and the information hinterland. There should be more innovations in financial sector of Shanghai, so there will be much non-standardized financial information in Shanghai. Such advantages could create cumulative causation effects and make Shanghai be the most important financial service 
hub of China. The effect of information asymmetry would push financial firms closer to an information source in order to find and interpret non-standardized information that a financial firm can use to make profit.

\section{References}

[1] Amin A, Thrift N. Living in the global[C]// Amin A, Thrift N. Globalization, Institutions and Regional Development in Europe. Oxford: Oxford University Press, 1994: 1-22.

[2] Thrift N. On the social and cultural determinants of international financial centres: The case of the city of London[C]// Corbridge S, Martin R, Thrift N. Money, Power and Space. Oxford: Blackwell, 1994: 327-355.

[3] Porteous D J. The geography of finance: Spatial dimensions of intermediary behaviour[M]. Aldershot: Avebury, 1995.

[4] Porteous D J. The development of financial centers: Location, information externalities and path dependence[C]// Martin R L. Money and the Space Economy. Chichester: Wiley, 1999: 95-114.

[5] Leyshon A, Thrift N. Money space: Geographies of monetary transformation[M]. London: Routledge, 1997.

[6] Dicken P. Global shift: Transforming the world economy[M]. London: Paul Chapman, 1998.

[7] Martin R L. The new economic geography of money[C]// Martin R L. Money and the Space Economy. Chichester: Wiley, 1999: 3-27.

[8] Martin R L. Institutional approaches in economic geography[C]// Barnes T, Sheppard E. A Companion to Economic Geography. Oxford: Blackwell, 2000: 77-94.

[9] Zhao X B, Zhang L, Wang T. Determining factors of the development of a national financial center: The case of China[J]. Geoforum, 2004, 35(4): 577-592.

[10] Zhao X B, Cai J M, Zhang L. Asymmetric information as a key determinant for location choice of MNC headquarters and the development of financial centers: A case for China $[J]$. China Economic Review, 2005(16): 308-331.

[11] Bourgain A, Patrice P. Measuring agglomeration forces in a financial center[J]. Economics Bulletin, 2006, 18(3): 1-9.

[12] Krugman P. Scale economies, product differentiation and the pattern of trade[J]. America Economic Review, 1980, 70(5): 950-959.

[13] Dixit A K, Stiglitz J E. Monopolistic competition and optimum product diversity[J]. The American Economic Review, 1977, 67(3): 297-308.

[14] Krugman P. Increasing returns and economic geography[J]. Journal of Political Economy, 1991, 99(3): 484-499.

[15] Fujita M, Krugman P, Venables A J. The spatial economy: Cities, regions and international trade[M]. Cambridge: MIT Press, 1999.

[16] Samuelson P A. The transfer problem and transport costs: the terms of trade when impediments are absent[J]. The Economic Journal, 1952(62): 278-304.

[17] Castells M. The informational city[M]. Oxford: Blackwell, 1989.

[18] Ohmae K. A world without borders[M]. NYC: Harper Business, 1990.

[19] Ohmae K. The end of the nation-state: The rise of regional economies[M]. London: Harper Collins, 1995.

[20] Kobrin S J. Electronic cash and the end of national markets[J]. Foreign Policy, 1997(4): 65-77. 